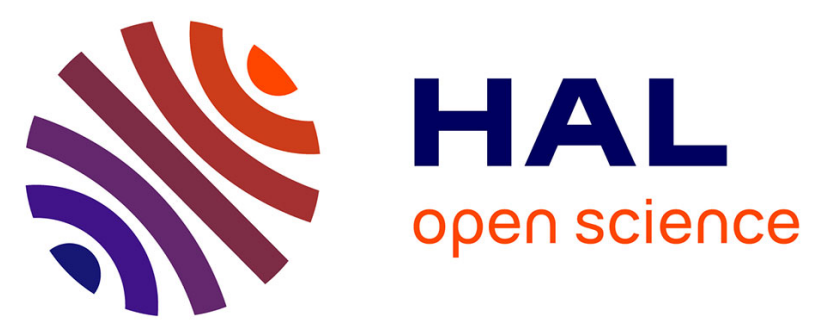

\title{
Sensitivity Analysis of a Light Fixed-wing Airborne TDEM System for the Characterization of Karstic Environments
}

\author{
G. A. Sab, C. Schamper, Fayçal Rejiba, Alain Tabbagh
}

\section{- To cite this version:}

G. A. Sab, C. Schamper, Fayçal Rejiba, Alain Tabbagh. Sensitivity Analysis of a Light Fixed-wing Airborne TDEM System for the Characterization of Karstic Environments. Near Surface Geoscience 2014 : 20th European Meeting of Environmental and Engineering Geophysics, Sep 2014, ATHENES, Greece. 10.3997/2214-4609.20142016 . hal-01142145

\section{HAL Id: hal-01142145 \\ https://hal.sorbonne-universite.fr/hal-01142145}

Submitted on 14 Apr 2015

HAL is a multi-disciplinary open access archive for the deposit and dissemination of scientific research documents, whether they are published or not. The documents may come from teaching and research institutions in France or abroad, or from public or private research centers.
L'archive ouverte pluridisciplinaire HAL, est destinée au dépôt et à la diffusion de documents scientifiques de niveau recherche, publiés ou non, émanant des établissements d'enseignement et de recherche français ou étrangers, des laboratoires publics ou privés. 
Tu PA1 13

\title{
Sensitivity Analysis of a Light Fixed-wing Airborne TDEM System for the Characterization of Karstic Environments
}

\author{
G.-A. Sab* (Sorbonne Universités-UPMC and Action Communication), C. \\ Schamper (Sorbonne Universités, UPMC/CNRS, UMR 7619 METIS), F. \\ Rejiba (Sorbonne Universités, UPMC/CNRS, UMR 7619 METIS) \& A. \\ Tabbagh (Sorbonne Universités, UPMC/CNRS, UMR 7619 METIS)
}

\section{SUMMARY}

Detailed mapping of karstic aquifers is of prime importance for water resources management. To achieve these surveys objectives, airborne measurements are the only methods which allow both large and dense coverage. Electromagnetic induction methods such as time-domain electromagnetic (TDEM) help to map conductors like clayey accumulations surrounding karstic conduits. Fixed-wing TDEM systems using light aircrafts do not exist on the market, despite being able to offer higher cost effectiveness and performance close to that reached with helicopter-borne EM systems in hydrogeological surveys. A sensitivity analysis of key acquisition parameters is undertaken to evaluate the capabilities of this kind of system for mapping karstic environments. Despite a flight altitude of $50 \mathrm{~m}$, higher than the average altitude of $30 \mathrm{~m}$ reached with helicopter-borne systems, the results are encouraging and indicate a good capacity for investigation from $10 \mathrm{~m}$ to about $150 \mathrm{~m}$ depth. 


\section{Introduction}

Hydrosystems are mostly present around Mediterranean Sea as karsts. Ground-based methods are not well suited for detailed mapping of such hydrosystems because of their poor sampling capabilities. Developments of efficient mapping techniques such as airborne systems are of high interest for the identification of the limits of karstic aquifers on vast surfaces (e.g. larger than $\left.100 \mathrm{~km}^{2}\right)$ with suited precision and sampling. In the present paper, we focus our interest on the time domain electromagnetic (TDEM) techniques which are electromagnetic induction methods that have already proven their efficiency in the mapping of good electrical conductors, from close to the surface to depths reaching several hundred meters. Expected good conductors in karstic environments are for instance clayey covers which are of prime importance in terms of protection against pollution and of hydrogeological modelling, because of their very low hydraulic conductivity.

Helicopter-borne electromagnetic (HEM) systems have proven to be efficient for mapping conductors in hydrogeological surveys (Siemon et al., 2009). Airborne TDEM systems were also developed during several decades from the 50s for fixed-wing aircrafts which are at least twin-engine (Fountain, 1998; Thomson et al., 2007). Those fixed-wing systems have several drawbacks: 1) they cannot fly as low as helicopters because of their size, and even if the receiver is towed behind the aircraft, it often remains well above $50 \mathrm{~m}$ from the ground while helicopter-borne systems are able to carry the receiver at a mean altitude of $30 \mathrm{~m} ; 2$ ) non obvious corrections are needed to compensate the oscillations of the towed receiver, while HEM systems have a rigid or semi-rigid structure which prevents variations of relative position between the transmitter and the receiver; 3) they consume as much fuel as helicopters contrary to light single-engine air planes. Since fixed-wing aircrafts have the advantage of having a longer autonomy than helicopters to easily cover large landscape, there is a potential interest in looking for an intermediate solution between helicopter-borne and present fixed-wing systems.

The solution considered in this paper is a light fixed-wing TDEM system which combines both costeffectiveness of fixed-wing systems and performances of helicopter-borne systems. Both transmitter (average surface of $550 \mathrm{~m}^{2}$ ) and receiver are towed behind the aircraft at an average altitude of $50 \mathrm{~m}$ and are linked together within a semi-rigid structure. Since such a system does not exist to our knowledge, a first sensitivity analysis is made in this paper to delimit the capabilities of this kind of system, focusing on the karstic environments.

First, a presentation of karstic systems is made with regard to the electrical resistivities encountered and the inherent difficulties of TDEM measurements in such environments. Several key acquisition parameters are then studied within wide ranges to identify the optimal parameters for surveys with a light fixed-wing aircraft.

\section{Karst systems and TDEM exploration}

Many geophysical surveys have already been focused on karst (e.g. a review from Chalikakis et al., 2011) using multiple different methods which have the capabilities of mapping different type of structures. Targets of interest in karst systems are sinkholes (filled by water or not), fractures (filled or not by water or clays), the epikarst, karst conduits, infiltration zones etc. Their studies have applications in geotechnics, and principally in water resource managements. It is estimated that at least a quarter of world's population is depending on karst systems for drinkable water.

Main component of karst systems is carbonate rocks which present high resistivities above $100 \Omega \mathrm{m}$, often close to $1000 \Omega \mathrm{m}$. If no salt water intrudes the karst system, the opposite conductive elements are clays which can be represented by thin filled fractures or cover layers of several meters thickness. Those clay units have low resistivities below tens of $\Omega \mathrm{m}$, often close to $10 \Omega \mathrm{m}$. This high contrast of resistivities (or large difference of conductivities) makes clay units good targets to map with electromagnetic induction methods ( $c f$. theory in Ward and Hohmann, 1988). However, the limited volume as well as the depth of those anomalies can make the mapping of those targets very challenging for EM induction methods whose resolution decreases inevitably with depth. 
Thin faults that spread over large surfaces could be mapped with multi-component EM measurements to detect 3D heterogeneities. However, if the conductor has a too low global volume and/or too large depth, and/or a too low resistivity contrast with the surrounding, the induced EM response remains undetectable. Very few airborne TDEM surveys have been successfully applied to karst environments, despite some of them have proven to bring better comprehension of the geology (e.g. surveys mentioned by Asch and Smith, 2012). In the present paper, we consider a karst system where clay layers of several meters thickness are present. Those targets are likely detectable with groundbased TDEM methods. The airborne methods introduce new parameters such as the flight altitude which can lower the resolution. In this specific context of karstic environment, we further study different key acquisition parameters to identify the limit of the technique, while considering the constraints imposed by the use of a light fixed-wing aircraft.

\section{Sensitivity analysis}

This analysis evaluates the impact of relevant parameters as a function of their value and of a conductive layer depth in a karstic-like environment. A $100 \Omega \mathrm{m}$ resistive ground is modelled (e.g. saturated chalk), in which a $10 \mathrm{~m}$ thick and $10 \Omega \mathrm{m}$ conductive layer (e.g. clay layer) takes place at a varying depth. Noise is also taken into account, with a noise level of $5 \mathrm{e}-9 \mathrm{~V} / \mathrm{m}^{2}$ at $1 \mathrm{~ms}$ and a noise slope of $\mathrm{t}^{-1 / 2}$. Each test result displays standard deviation factor (STDf) estimated from the linearized approximation of the covariance matrix by AarhusInv program (Auken and Christiansen, 2004). Each plot has the same structure: the range of values for the studied acquisition parameter on the $\mathrm{x}$ axis, and the range of depths for the conductive layer on the y axis.

Figure 1 displays results of the sensitivity analysis regarding flight altitude. It estimates how well the system can solve the depth of the upper interface of the conductive layer. STDf values from 1 to 2 mean that the layer depth is well estimated, whereas values beyond 3 mean that the depth is poorly resolved. The STDf value of 3.5 is a commodity to display the "-1" value obtained with the program, which warns that the system has no sensitivity at all. Figure 1 clearly shows the loss of sensitivity for deep layers with increasing flight altitude. At $50 \mathrm{~m}$ flight altitude, the layer depth is not resolved below $160 \mathrm{~m}$. Regarding the near surface, a loss in sensitivity is observed with a zone of poor sensitivity enlarging with the increase of the altitude. If flight altitude below $30 \mathrm{~m}$ is possible, the sensitivity would be good for depths below $10 \mathrm{~m}$. But from a nominal flight altitude of $50 \mathrm{~m}$, there is no sensitivity for such shallow depths. From the depth of $10 \mathrm{~m}$ the sensitivity already starts to be good, probably due to the first acquired gate which is quite early, $11 \mu \mathrm{s}$ from the beginning (and $1 \mu \mathrm{s}$ from the end) of the turn off ramp for this test.

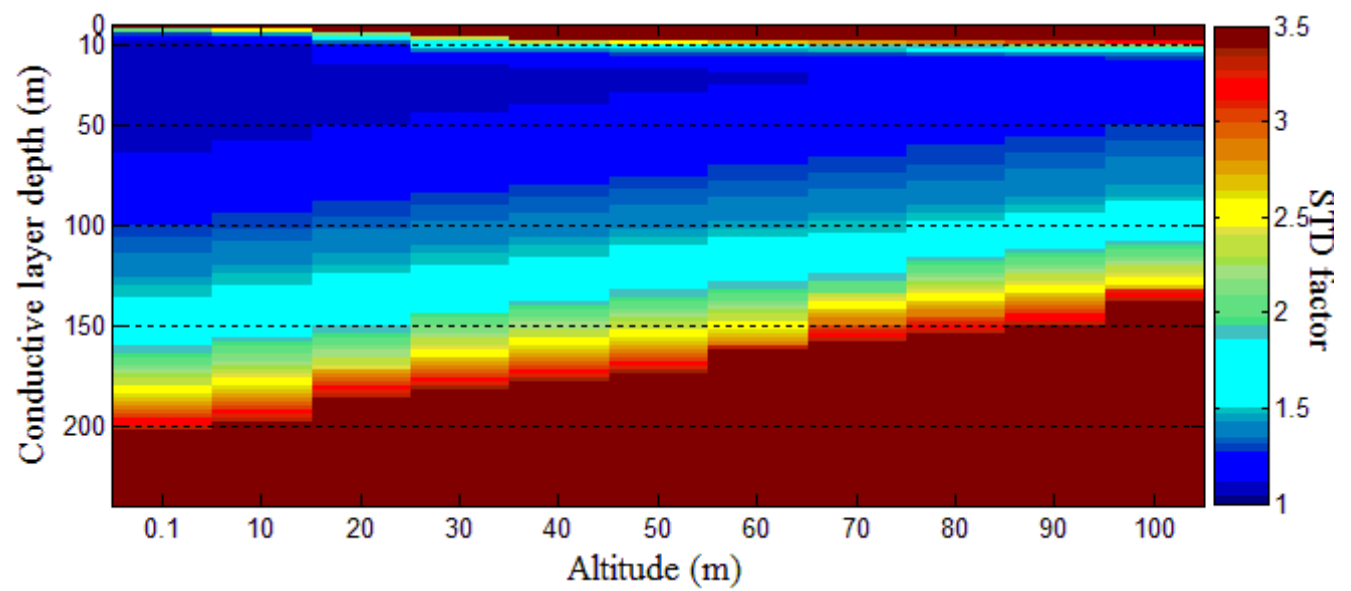

Figure 1 Sensitivity analysis on the flight altitude. STDf is calculated for a 3-layer model where a $10 \mathrm{~m}$ thick conductive layer of $10 \Omega \mathrm{m}$ has its depth varying within a $100 \Omega \mathrm{m}$ halfspace.

Figure 2 aims to validate the assumption that near-surface sensitivity is improved by earlier recording times. Electronics imposes a duality between the turn-off ramp duration and the maximum intensity of the pulse. A shorter turn-off ramp needs a lower intensity. That is why Figure 2 shows results of the 
sensitivity analysis on both intensity and turn-off duration. In the present case, they are linked by a linear function which takes expected reachable performances into account: $I=(40 / 3) \cdot t-(250 / 3)$ with $I$ the intensity in amperes and $t$ the turn-off ramp in $\mu$ s. Figure 2 indicates that turn-off ramps longer than $16 \mu$ s prevent the system from having good near-surface sensitivity in the first $20 \mathrm{~m}$. It also shows that a better sensitivity in depth (or better depth of investigation) is obtained with longer turn-off times which correspond to higher intensities, and then better signal-to-noise ratio at late times. Configurations chosen for other tests have a turn-off ramp of $10 \mu \mathrm{s}$.

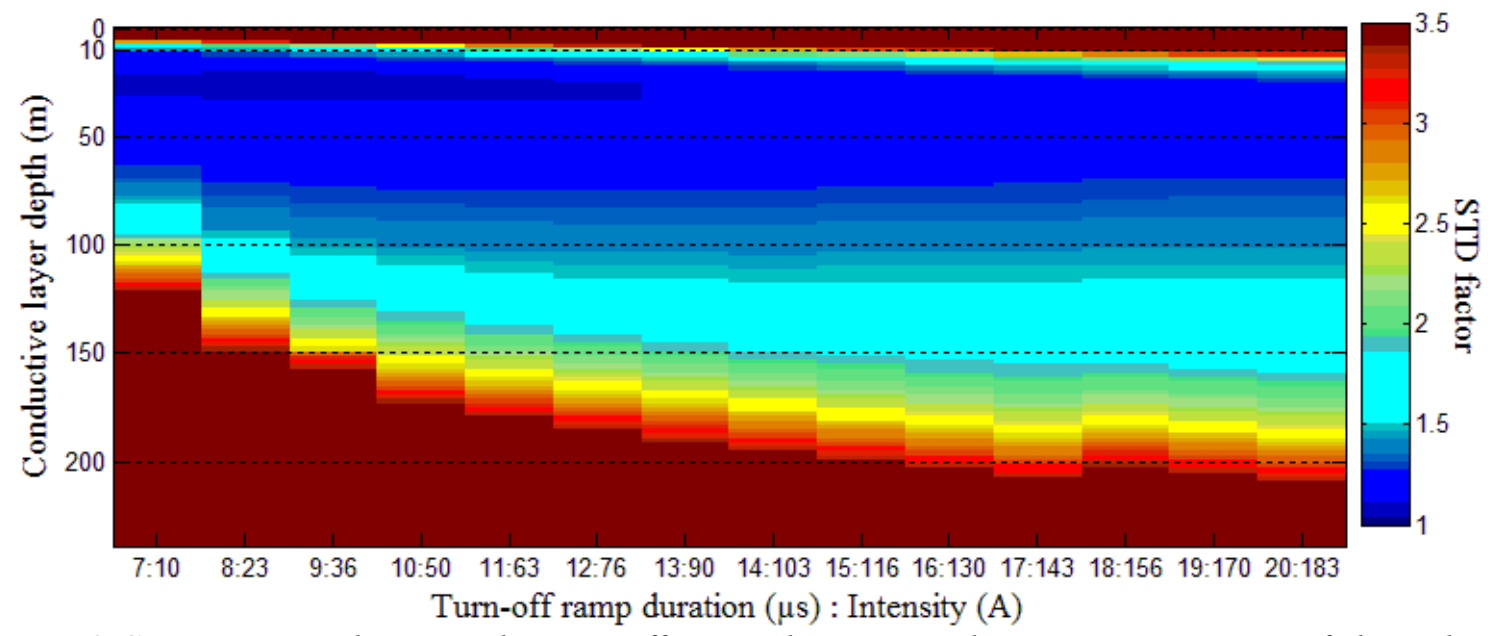

Figure 2 Sensitivity analysis on the turn-off ramp duration and maximum intensity of the pulse. A pulse intensity is assigned to each turn-off ramp duration following a linear relation. The STDf is estimated in the same way as for Figure 1, and for the same tabular ground.

Similarly as Figures 1 and 2, Figure 3 illustrates the impact of the pulse duration on the estimation of the conductive layer depth. For this analysis, on-time and off-time periods are equal (50\% duty cycle), which means that the last recording time is identical to the on-time period. For this specific test, noise level modelled is lowered from $5 \mathrm{e}-9$ to $5 \mathrm{e}-10 \mathrm{~V} / \mathrm{m}^{2}$ so that only the recording period influences the analysis, and not the level of the TDEM response compared to the noise level. Indeed, if the noise level is reached at a certain time, any later gate is automatically removed and no more change in sensitivity is observed. Figure 3 shows that pulse duration impacts sensitivity at largest depths (with an improvement until an on-time period of $5 \mathrm{~ms}$ ), which is mainly due to the longer recording time associated to a longer pulse. As expected, pulse duration has no effect on near-surface sensitivity (down to $50 \mathrm{~m}$ when pulse is $1 \mathrm{~ms}$ long). In the case of near-surface surveys, short recording time is then recommended. It implies higher acquisition frequency, so a better lateral resolution.

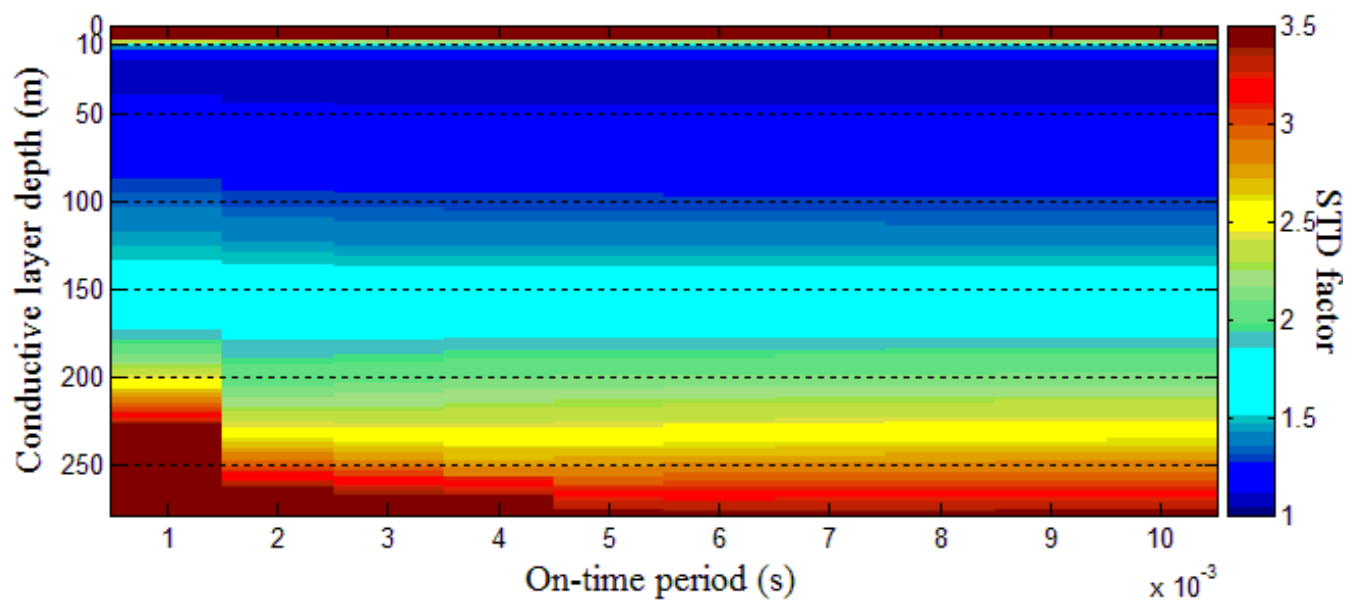

Figure 3 Sensitivity analysis on pulse duration and recording period. STDf is estimated in the same way as for Figures 1 and 2, and for the same tabular ground. Pulse duration (i.e. on-time period) and recording period are identical (50\% duty cycle). 


\section{Conclusion and discussion}

It has been shown that the flight altitude of a light fixed-wing TDEM system $(50 \mathrm{~m})$ does not prevent good near-surface sensitivity (from $10 \mathrm{~m}$ depth). To be able to detect a near-surface conductive layer (e.g. clay cover layer), analysis shows that it is necessary to have a first recorded gate at $\sim 11 \mu$ s or less from the beginning of the turn-off ramp. On the other hand, it is necessary to have a turn-off ramp longer than $11 \mu \mathrm{s}$ in order to obtain good sensitivity below $150 \mathrm{~m}$ depth. This is due to the inevitable link between the turn-off speed and the intensity of the injected current in the emitting loop. Therefore, the shape of the waveform needs to be designed according to the depth of the targeted conductor. Pulse duration coupled with longer recording period is another way to improve the sensitivity at larger depths. However, analysis with noise level $\geq 0.5 \mathrm{nV} / \mathrm{m}^{2}$ (level at $1 \mathrm{~ms}$ ) demonstrates that pulse duration have very little impact in the context of resistive grounds like carbonate rocks. This is due to the moment of the system being too low to obtain late time measures with reasonable accuracy, making inefficient the use of late recording times. Intensity of the current absolutely needs to be considered in order to take benefit of late measurements, especially for airborne measurements where stack period is naturally limited compared to ground-based measures. If high current is not available, we recommend the use short on and off-times (e.g. 1ms) even when expected depth of the first conductive layer is large (from 150m). This will allow higher repetition frequency and higher lateral resolution of the top part.

To conclude, such a light fixed-wing TDEM system is expected to be sensitive between 10 and $160 \mathrm{~m}$ above karstic environments. It has however to be underlined that this analysis considers relatively large conductive anomalies like several meters thick clay layers. For other targets of interest in karstic environment such as 3D fault structures or volume limited sinkholes, more advanced and site-specific studies are needed.

\section{Acknowledgements}

The authors of this paper thank Action Air Environnement - S.A.S. Action Communication for the authorization to present this work.

\section{References}

Asch, T.H. and Smith, B.D. [2012] Design of an Airborne EM Survey over the Dead Sea. EAGE Workshop on Dead Sea Sinkholes - Causes, Effects \& Solutions, Extended Abstracts, DS11.

Auken, E. and Christiansen, A.V. [2004] Layered and laterally constrained 2D inversion of resistivity data. Geophysics, 69, 752-761.

Chalikakis, K., Plagnes, V., Guérin, R., Valois, R. and Bosch, F.P. [2011] Contribution of geophysical methods to karst-system exploration: an overview. Hydrogeology Journal, 19, 1169-1180.

Fountain, D. [1998] Airborne electromagnetic systems - 50 years of development. Exploration Geophysics, 29, 1-11.

Siemon, B., Christiansen, A.V. and Auken, E. [2009] A review of helicopter-borne electromagnetic methods for groundwater exploration. Surface Geophysics, 7, 629-646.

Thomson, S., Fountain, D. and Watts, T. [2007] Airborne geophysics-Evolution and revolution. Proceedings of Exploration, 19-37.

Ward, S.H. and Hohmann, G.W. [1988] Electromagnetic theory for geophysical applications. Electromagnetic Methods in Applied Geophysics, 1, Nabighian, M.N., 131-311. 